\title{
Quercetin protects neuronal cells from oxidative stress and cognitive degradation induced by amyloid $\beta$-peptide treatment
}

\author{
YAN-LING LI ${ }^{1 *}$, HUA GUO $^{2 *}$, YONG-QIANG ZHAO ${ }^{3}$, AI-FAN LI $^{1}$, YUE-QIN REN ${ }^{4}$ and JIE-WEN ZHANG ${ }^{5}$ \\ ${ }^{1}$ Department of Neurology, Zhengzhou First People's Hospital, Zhengzhou, Henan 450004; ${ }^{2}$ Department of Medicine Imaging, \\ The First Affiliated Hospital of Henan University of Science and Technology, Luoyang, Henan 471003; ${ }^{3}$ Department of \\ Endocrinology, Anyang District Hospital, Anyang, Henan 455000; ${ }^{4}$ Department of Radiology Magnetic Resonance, \\ The Second Affiliated Hospital of Henan Traditional Chinese Medicine University; ${ }^{5}$ Department of Neurology, \\ The People's Hospital of Zhengzhou University, Zhengzhou, Henan 450000, P.R. China
}

Received March 26, 2016; Accepted January 30, 2017

DOI: $10.3892 / \mathrm{mmr} .2017 .6704$

\begin{abstract}
The present study aimed to investigate the effect of quercetin on cytotoxicity and cognitive degradation induced by amyloid $\beta(\mathrm{A} \beta)$-peptide in mice. Using the 1,1-diphenyl-2-picrylhydrazyl (DPPH) method and a Y-maze assay, the radical quenching ability and effect on working memory were determined, respectively, of quercetin treatment following 4 days of $\mathrm{A} \beta$ administration. The acute oral toxicity was assessed used to determine the concentration of quercetin at which $50 \%$ lethality of the neuronal cells was induced. For determination of the effect of quercetin on degradation of learning and memory loss induced by $\mathrm{A} \beta$, a passive avoidance test was used. The results revealed that quercetin was involved in the inhibition of DPPH radical activity and was found to reduce radical activity by $76.5 \%$. Quercetin significantly protected PC12 neuronal cells from death induced by $\mathrm{A} \beta$ treatment. Treatment of mice with daily doses of $100 \mathrm{mg} / \mathrm{kg}$ body weight quercetin for 30 days significantly improved the degradation of learning and memory loss induced by $\mathrm{A} \beta$. The acute oral dose of quercetin in mice was determined to be $575 \mathrm{mg} / \mathrm{kg}$ body weight. Therefore, quercetin was found to be of therapeutic value for the treatment of neurological disorders, including $\mathrm{AD}$, although further investigations are required.
\end{abstract}

\section{Introduction}

Alzheimer's disease (AD) represents the most common cause of dementia in the aged population, and is characterized by

Correspondence to: Dr Jie-Wen Zhang, Department of Neurology, The People's Hospital of Zhengzhou University, 5 Wei Road, Zhengzhou, Henan 450000, P.R. China

E-mail: zhangjiewen9900@126.com

${ }^{*}$ Contributed equally

Key words: Alzheimer's disease, quercetin, flavonoid, oral dose, lethality, working memory the degradation of memory and cognitive function (1). AD is characterized by the aggregation of extracellular senile plaques, which are comprised of amyloid $\beta(\mathrm{A} \beta)$ precursor protein and intracellular neurofibrillary tangles $(2,3)$. The mechanism underlying the pathology of $\mathrm{AD}$ remains to be fully elucidated, however, it has been suggested that the mitochondrial pathway may be involved in the induction of cell apoptosis (1-3). Studies have shown that increased oxygen consumption, excess concentrations of polyunsaturated fatty acids and reduced quantities of antioxidants in the brain render it sensitive to oxidative stress $(4,5)$. A $\beta$ generates free radicals or causes neuronal death during oxidative stress $(6,7)$. The brain tissues of patients with AD have shown higher concentrations of nitric oxide species and oxidized proteins $(8,9)$. In addition, the peroxidation of membrane lipids has been reported in the brain tissues of patients with AD $(10,11)$. Therefore, the screening of natural antioxidant products may lead to the identification of potential molecules for the treatment of AD.

Quercetin (3,3',4',5,7-pentahydroxyflavone; Fig. 1), a member of the flavonoid family is a well-known antioxidant (12). Due to their structural features, flavonoids possess the promising ability to transfer electrons to free radicals, induce antioxidant enzyme activation and suppress oxidative stress (13). The presence of a catechol group and an -OH group in quercetin imparts improved ability to act as an antioxidant agent. The presence of these structural features in quercetin enables it to act as a hydrogen donor for quenching free radicals (14). Quercetin has been shown to possess a wide range of biological activities, which include antioxidant, antifibrotic and antiinflammatory activities. Previous in vitro studies have demonstrated that quercetin exhibits the ability to quench oxygen free radicals, suppress the peroxidation of membrane lipids and alter the redox status of glutathione $(15,16)$. Quercetin-induced improvements in the inflammatory processes have been found to be associated with the generation of inducible nitric oxide synthase and tumor necrosis factor- $\alpha$ (17). In addition, quercetin suppresses the proliferation of keloid fibroblasts, generation of collagen and reduction in keloid through the inhibition of transforming growth factor- $\beta /$ small mothers against decapentaplegic signaling pathway (18). The present study investigated the role 
of quercetin in protecting against neuronal cell death, and in the inhibition of $A \beta$ peptide-induced degradation of cognition and memory loss. The results revealed that quercetin treatment prevented neuronal cell death, and inhibited the degradation of cognition and memory loss induced by $\mathrm{A} \beta$. Therefore, quercetin is of therapeutic importance for the treatment of neurodegenerative diseases, including AD.

\section{Materials and methods}

Chemicals and materials. Quercetin, A $\beta 1-42$ and fetal bovine serum (FBS) were obtained from Sigma-Aldrich (Merck Millipore, Darmstadt, Germany). The 3-(4,5-dimethylthiazol-2-yl)-2,5-diphenyltetrazolium bromide (MTT) was purchased from Bachem (Bubendorf, Switzerland). Dimethyl sulfoxide and other common chemicals were obtained from Sigma-Aldrich (Merck Millipore).

Cell culture. The PC12 rat pheochromocytoma cell line was purchased from the Japanese Collection of Research Bioresources (Shinjuku, Japan). The cells were cultured in minimum essential medium (Gibco; Thermo Fisher Scientific, Inc., Waltham, MA, USA) supplemented with 10\% FBS and $1 \%$ penicillin/streptomycin. The cell cultures were maintained in a $\mathrm{CO}_{2}$ incubator at $37^{\circ} \mathrm{C}$ with a controlled humidified atmosphere of $95 \%$ air and $5 \% \mathrm{CO}_{2}$.

1,1-diphenyl-2-picrylhydrazyl (DPPH). The DPPH• radical scavenging activity assay is widely used to evaluate the antioxidant activity of compounds. The ability of a compound to interact with the stable DPPH free radical indicates its capacity to quench free radicals. Quercetin treatment exhibits antiradical activity by inhibiting DPPH radicals. For investigating the radical scavenging activities, $10 \mathrm{mM}$ quercetin in methyl alcohol was further diluted using methyl alcohol to obtain 5, 10, 20, 50 and $100 \mu \mathrm{M}$ solutions. To each of the solutions of quercetin, $0.25 \mathrm{mM}$ DPPH (Santa Cruz Biotechnology, Inc.) was added, followed by incubation for $45 \mathrm{~min}$ at room temperature. The optical density of each of the solutions was then measured using a spectrophotometer at $519 \mathrm{~nm}$. The control used was pure ethyl alcohol and its absorbance was denoted as A0, whereas the absorbance of the sample solution was denoted asAq. The scavenging activity of quercetin was calculated using the following equation: Scavenging activity $(\%)=\left[\left(\mathrm{A}_{0}-\mathrm{A}_{\mathrm{q}}\right) / \mathrm{A}_{0}\right] \times 100$.

Cell viability assay. The effects on cell viability and the neuroprotective effect exhibited by quercetin were determined using an MTT assay. For this purpose, cells at a density of $2 \times 10^{4}$ cells per well were distributed onto 96-well plates and cultured overnight. The media were then removed and the cells were exposed to either saline as a control, selegiline $(10 \mu \mathrm{M})$ as a positive control or different quercetin $(10-100 \mu \mathrm{M})$ and incubated for $48 \mathrm{~h}$ at $37^{\circ} \mathrm{C}$. Following incubation, MTT solution was added to each of the wells and the plates were incubated for $2 \mathrm{~h}$ at $37^{\circ} \mathrm{C}$. Dimethyl sulfoxide was added to the wells for dissolution of the formazan crystals, which had formed. A microplate reader (Model 550; Bio-Rad Laboratories, Inc., Hercules, CA, USA) was used to measure the absorbance at $540 \mathrm{~nm}$. For each of the analyses, three replicate wells were used.<smiles>O=c1c(O)c(-c2ccc(O)c(O)c2)oc2cc(O)cc(O)c12</smiles>

Figure 1. Chemical structure of quercetin.

Animals. Male ICR mice ( $\mathrm{n}=25 ; 6-8$ weeks old; weight, 18-20 g) were purchased from the Experimental Animal Center of Sichuan University (Chengdu, China). The mice were acclimatized to the laboratory environment 1 week prior to commencement of the experiments, and were housed in a room with a $12 \mathrm{~h}$ light and dark cycle at a temperature of $25^{\circ} \mathrm{C}$. The animals had access to standard food and water ad libitum. All animal experimental procedures were performed following approval from the Laboratory Animal Care Committee of Sichuan Province (Sichuan, China).

Treatment strategy. The animals were randomly assigned into five groups, each containing five animals: i) control, ii) $\mathrm{A} \beta$ treatment, iii) quercetin $50 \mathrm{mg} / \mathrm{kg}$ body weight followed by $\mathrm{A} \beta$ treatment, iv) quercetin $100 \mathrm{mg} / \mathrm{kg}$ body weight followed by $\mathrm{A} \beta$ treatment; v) selegiline $3 \mathrm{mg} / \mathrm{kg}$ body weight followed by $A \beta$ treatment. Quercetin was dissolved in tap water and administered orally every day for one month, at doses of 50 or $100 \mathrm{mg} / \mathrm{kg} /$ body weight. A $\beta 1-42$ (20 mg/kg/body weight) was administered to mice through injection following quercetin pretreatment.

$Y$-maze test. For determination of the role of quercetin on spatial working memory following 4 days of $A \beta$ injections, a Y-maze test was performed. The instrument consisted of a maze, which was $35 \mathrm{~cm}$ in length, $16 \mathrm{~cm}$ in height and $12 \mathrm{~cm}$ in width. The instrument has arms, which are projected symmetrically. The mice were placed in one of the arms and allowed to enter the other arms for $10 \mathrm{~min}$. During this period, the number of arms mice entered was calculated, from which the percentage alternation was calculated as follows: Alternation $(\%)=[($ number of alternations $) /($ total arm entries-2) $] \times 100$.

Passive avoidance test. The determination of the role of quercetin on learning and memory following 6 days of $A \beta$ injection was performed using a passive avoidance test. The instrument consists of a double compartment step-through passive avoidance apparatus (Model PACS-30; Columbus Instruments International, Columbus, OH, USA). Internally, the instrument had two similar chambers $(24 \times 16 \times 16 \mathrm{~cm})$. One of the chambers contained a bulb for lighting, whereas the second chamber was covered with black film. The mice from the lit chamber were allowed to enter the dark chamber by the raising of a door, where they received a $1 \mathrm{sec}$ foot shock during the training period. Training consisted of two 5-day sessions, with 4 trials per session. The intersession gap was $2 \mathrm{~h}$ and inter-trial gap was $30 \mathrm{sec}$. Following the completion of training, the latency period taken to enter the dark chamber for each mouse was recorded. 


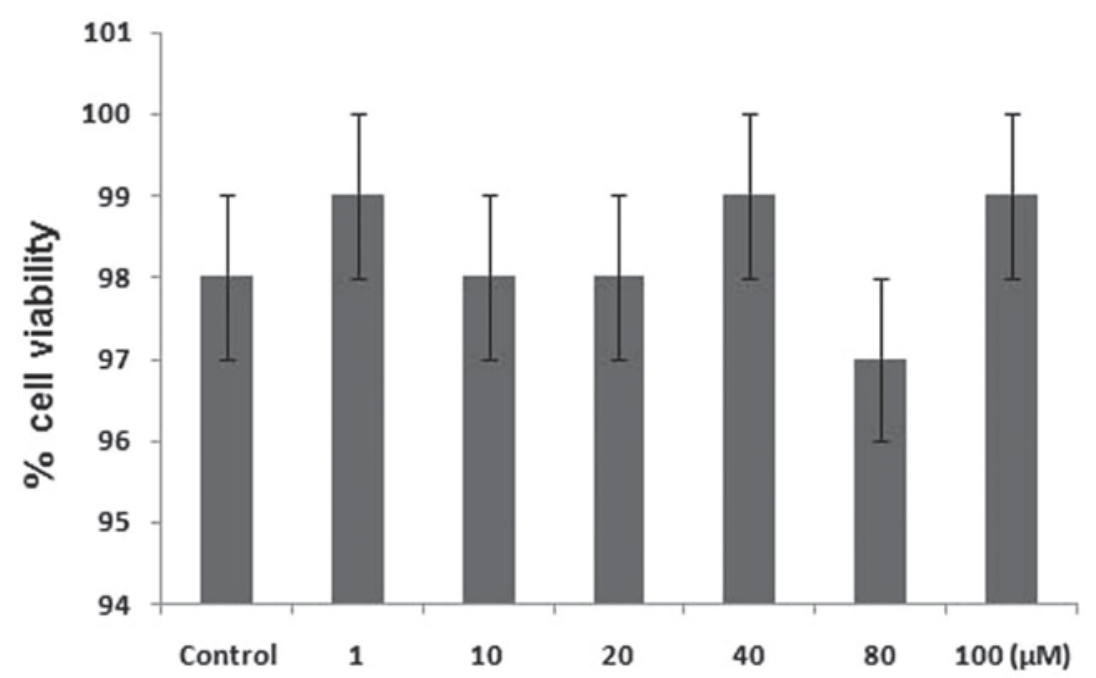

Figure 2. Quercetin treatment has no significant effect on the viability of PC12 cells. PC12 cells were exposed to different concentrations of quercetin for $24 \mathrm{~h}$ and cell viability was examined using a 3-(4,5-dimethylthiazol-2-yl)-2,5-diphenyltetrazolium bromide assay. The data is presented as the mean percentage of viable cells.

Determination of acute oral toxicity. To determine the acute oral toxicity induced by quercetin treatment in the mice, a lethality assay was used. Briefly, the mice were divided into five groups of five mice. The mice in the control group received normal saline and carboxymethyl cellulose (CMC). The mice in the treatment groups were administered with saline, CMC and quercetin in DMSO at concentrations of 50, 80 and $100 \mathrm{mg} / \mathrm{kg}$ body weight. The animals were examined following the administration of the doses for $100 \mathrm{~h}$. For calculation of the acute toxic dose ( $\mathrm{mg} / \mathrm{kg}$ body weight), resulting in death of $50 \%$ of the mice $\left(\mathrm{LD}_{50}\right)$ was determined using the Sigma plot version 12 program (Sigma-Aldrich).

Statistical analysis. All data are presented as the mean \pm standard error of the mean. Student's t-test was used for statistical comparisons. All statistical tests were calculated using SPSS 13.0 software (SPSS, Inc., Chicago, IL, USA). $\mathrm{P}<0.05$ was considered to indicate a statistically significant differences.

\section{Results}

Effect of quercetin treatment onPC12 cell toxicity. The primary factor examined in determining the anti-oxidant nature of a compound is its scavenging activity for oxygen radicals (19). The results revealed that quercetin was potentially involved in the inhibition of DPPH radical activity. It reduced the radical activity of DPPH by $76.5 \%$. To investigate the effect of quercetin on the viability of PC12 cells, an MTT assay was used. The results showed that treatment of the PC12 cells with different concentrations of quercetin for $24 \mathrm{~h}$ induce no toxicity (Fig. 2).

Protective effect of quercetin against $A \beta$-induced cell cytotoxicity in PC12 cells. For investigating the effect of quercetin on the reduced viability of PC12 cells induced by A $\beta$ treatment, an MTT assay was used. The PC12 cells were exposed to a range of quercetin concentrations (10-100 $\mu \mathrm{M})$ prior to incubation with $\mathrm{A} \beta$. The results revealed that pretreatment of the PC12 cells with quercetin inhibited the decrease in cell viability induced by $A \beta$ (Fig. 3). The rates of cell viability in the cells exposed to quercetin prior to $A \beta$ treatment and in the A $\beta$-only treated cells were 97 and 28\%, respectively, compared with $98 \%$ in the control cells (Fig. 3). Pretreatment of the cells with quercetin exhibited a concentration-dependent effect on the inhibition of cell viability. The inhibition of the $\mathrm{A} \beta$-induced reduction in $\mathrm{PC} 12$ cell viability by quercetin was significant $(\mathrm{P}<0.002)$ at a concentration of $100 \mu \mathrm{M}$ after $24 \mathrm{~h}$. These findings indicated that quercetin exhibited a protective effect against $\mathrm{A} \beta$-induced cytotoxicity in the PC12 cells.

Quercetin inhibits $A \beta$-induced memory degeneration in mice. Examination of the A $\beta 1-42$-injected group of mice showed a marked decrease in behavioral alternations, compared with the untreated group $(\mathrm{P}<0.05$; Fig. $4 \mathrm{~A})$. By contrast, treatment of the mice with quercetin prior to $A \beta 1-42$-injection prevented the behavioral alternations induced by $A \beta 1-42$. Treatment of the mice with 50 and $100 \mathrm{mg} / \mathrm{kg}$ body weight of quercetin led to spatial working memory of 14.4 and $19.5 \%$, respectively.

The learning ability of the mice was examined by measuring response latency, which revealed that treatment of the mice with A $\beta 1-42$ led to the degradation of learning ability, compared with the untreated rats. Compared with the control group with a latency of $199.3 \mathrm{sec}$, the latency in the A $\beta 1-42$-treated group was $85.0 \mathrm{sec}$. However, treatment of the mice with quercetin significantly inhibited $A \beta$-induced memory degeneration, compared with the control (Fig. 4B). The inhibition of A $\beta$-induced memory degeneration by quercetin was significantly higher, compared with that by selegiline, which was used as the positive control. In terms of the selegiline-treated group of mice, the latency was $155 \mathrm{sec}(\mathrm{P}<0.05)$. Therefore, quercetin treatment exhibited a potential inhibitory effect on the degeneration of learning memory in mice.

$L D_{50}$ of quercetin in mice. The mice were administered with a single dose of quercetin followed by examination of their 
Table I. Quercetin-induced effects in mice following oral administration.

\begin{tabular}{rcccc}
\hline Quercetin $(\mathrm{mg} / \mathrm{kg})$ & Total mice $(\mathrm{n})$ & Deaths $(\mathrm{n})$ & Latency $(\mathrm{h})$ & Symptoms \\
\hline 0 & 5 & 0 & - & - \\
100 & 5 & 0 & - & Reduced walking speed; hair loss \\
400 & 5 & 1 & $>28$ & Reduced walking speed; hair loss; unconsciousness. \\
800 & 5 & 4 & $>30$ & \\
\hline
\end{tabular}

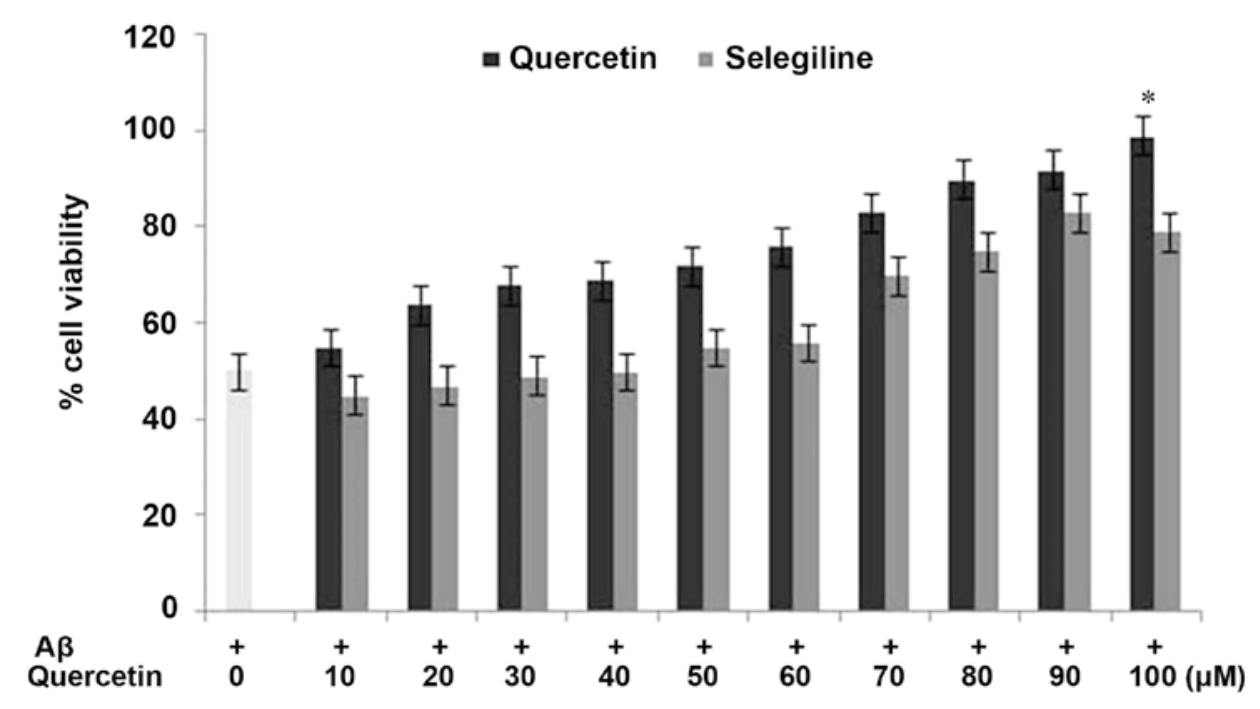

Figure 3. Quercetin provides protection against the cell damaging effects induced by A $\beta 1$ treatment. A3-(4,5-dimethylthiazol-2-yl)-2,5-diphenyltetrazolium bromide assay was used to examine cell viability following quercetin treatment. Selegiline was used as a positive control. "P<0.002 vs. A $\beta$ treatment group. $\mathrm{A} \beta$, amyloid $\beta$.
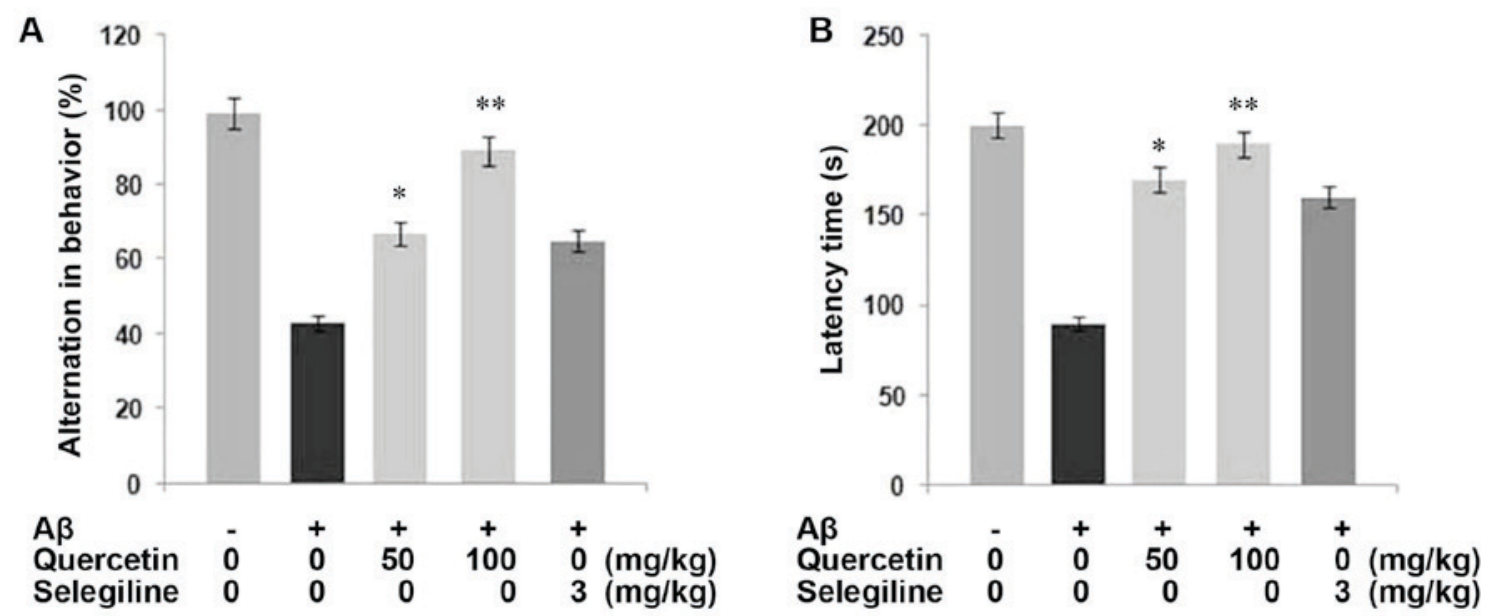

Figure 4. Quercetin prevents behavior alternations in mice induced by A $\beta$ treatment. (A) To examine alternations in behavior, a Y-maze test was used. (B) To assess the degradation of memory, step-through latency was determined in a passive avoidance task. ${ }^{*} \mathrm{P}<0.002$ and ${ }^{* *} \mathrm{P}<0.005$ vs. control group. $\mathrm{A} \beta$, amyloid $\beta$.

alterations in behavior and number of deaths over a period of $100 \mathrm{~h}$. The results showed a concentration-dependent enhancement in behavioral alterations and the number of deaths. The administration of $100 \mathrm{mg} / \mathrm{kg}$ of quercetin resulted in a mortality rate of $72 \%$ within the $100 \mathrm{~h}$ treatment period, with altered behavior observed in the remaining mice (Table I). The behavioral alterations induced by quercetin treatment included reduced walking speed, hair loss and unconsciousness. The
$\mathrm{LD}_{50}$ value of orally administered quercetin was estimated to be $575 \mathrm{mg} / \mathrm{kg}$ body weight in the mice.

\section{Discussion}

The present study aimed to investigate the effect of quercetin on protection against neuronal cell death, $A \beta$-induced oxidative stress and memory degradation. To investigate the 
anti-oxidant nature of a compound, a scavenging activity assay against oxygen species is used (19). In neurological disorders, including AD, the dysfunction of neurons and their death has been found to be associated with oxidative stress $(20,21)$. Previous in vitro studies have demonstrated that quercetin has a promising ability at quenching oxygen free radicals, suppressing the peroxidation of membrane lipids and altering the redox status of glutathione $(15,16)$. The results of the present study revealed that quercetin had a potential role in the inhibition of DPPH radical activity, and reduced radical activity by $76.5 \%$. Treatment of the PC12 cells with different concentrations of quercetin for $24 \mathrm{~h}$ induced no toxic effects.

It has been reported that the presence of $A \beta$ peptide is responsible for the production of reactive oxygen species, which in turn induces the peroxidation of membrane lipids and cell apoptosis $(22,23)$. There are reports that antioxidants prevent neurons from apoptosis, and can inhibit the degradation of cognition and prevent memory loss induced by the $A \beta$ peptide (24). Extracted brain tissue specimens from patients with AD have also shown the presence of peroxidized lipids, modified proteins and oxidized DNA in cells (25). The results of the present study demonstrated that quercetin treatment prevented the neuronal cells from $A \beta$-induced cytotoxicity. Quercetin treatment also protected the cells from $\mathrm{A} \beta$-induced degradation of learning and loss of memory. It appeared that the protective effect of quercetin was the result of its ability to inhibit oxidative stress by quenching reactive oxygen species.

For any biologically active molecule, the determination of acute oral toxicity is an important parameter. The results of the present study revealed that quercetin had a significantly lower toxicity, compared with selegiline. In conclusion, quercetin treatment prevented neuronal cells from $\mathrm{A} \beta$-induced oxidative stress, and prevented the degradation of learning and loss of memory induced by $A \beta$. Therefore, quercetin may be a potential candidate for the prevention of $\mathrm{AD}$.

\section{References}

1. Zhu Y, Li C, Sun A, Wang Y and Zhou S: Quantification of microRNA-210 in the cerebrospinal fluid and serum: Implications for Alzheimer's disease. Exp Ther Med 9: 1013-1017, 2015.

2. Chambers JK, Uchida K, Harada T, Tsuboi M, Sato M, Kubo M, Kawaguchi H, Miyoshi N, Tsujimoto $\mathrm{H}$ and Nakayama $\mathrm{H}$ : Neurofibrillary tangles and the deposition of a beta amyloid peptide with a novel-N-terminal epitope in the brains of wild Tsushima leopard cats. PLoS One 7: e46452, 2012.

3. Guo J, Chang L, Zhang X, Pei S, Yu M and Gao J: Ginsenoside compound $\mathrm{K}$ promotes $\beta$-amyloid peptide clearance in primary astrocytes via autophagy enhancement. Exp Ther Med 8: 1271-1274, 2014

4. Floyd RA and Hensley K: Oxidative stress in brain aging. Implications for therapeutics of neurodegenerative diseases. Neurobiol Aging 23: 795-807, 2002.

5. Mattson MP, Chan SL and Duan W: Modification of brain aging and neurodegenerative disorders by genes, diet, and behavior. Physiol Rev 82: 637-672, 2002.
6. Huang X, Atwood CS, Hartshorn MA, Multhaup G, Goldstein LE, Scarpa RC, Cuajungco MP, Gray DN, Lim J, Moir RD, et al: The A beta peptide of Alzheimer's disease directly produces hydrogen peroxide through metal ion reduction. Biochemistry 38 : 7609-7616, 1999.

7. Christen Y: Oxidative stress and Alzheimer disease. Am J Clin Nutr 71: 621s-629s, 2000.

8. Sultana R, Perluigi M and Butterfield DA: Oxidatively modified proteins in Alzheimer's disease (AD), mild cognitive impairment and animal models of AD: Role of Abeta in pathogenesis. Acta Neuropathol 118: 131-150, 2009.

9. Zhu X, Su B, Wang X, Smith MA and Perry G: Causes of oxidative stress in Alzheimer disease. Cell Mol Life Sci 64: 2202-2210, 2007.

10. Mark RJ, Lovell MA, Markesbery WR, Uchida K and Mattson MP: A role for 4-hydroxynonenal, an aldehydic product of lipid peroxidation, in disruption of ion homeostasis and neuronal death induced by amyloid beta-peptide. J Neurochem 68: 255-264, 1997.

11. Butterfield DA, Hensley K, Harris M, Mattson M and Carney J: beta-amyloid peptide free radical fragments initiates synaptosomal lipoperoxidation in a sequence-specific fashion: Implications to Alzheimer's disease. Biochem Biophys Res Commun 200: 710-715, 1994.

12. Kelly GS: Quercetin. Monograph. Altern Med Rev 16: 172-194, 2011.

13. Heim KE, Tagliaferro AR and Bobilya DJ: Flavonoid antioxidants: Chemistry, metabolism and structure-activity relationships. J Nutr Biochem 13: 572-584, 2002.

14. Heijnen CG, Haenen GR, Oostveen RM, Stalpers EM and Bast A: Protection of flavonoids against lipid peroxidation: The structure activity relationship revisited. Free Radic Res 36: 575-581, 2002.

15. Cai Q, Rahn RO and Zhang R: Dietary flavonoids, quercetin, luteolin and genistein, reduce oxidative DNA damage and lipid peroxidation and quench free radicals. Cancer Lett 119: 99-107, 1997.

16. Meyers KJ, Rudolf JL and Mitchell AE: Influence of dietary quercetin on glutathione redox status in mice. J Agric Food Chem 56: 830-836, 2008

17. Rivera L, Morón R, Sánchez M, Zarzuelo A and Galisteo M: Quercetin ameliorates metabolic syndrome and improves the inflammatory status in obese Zucker rats. Obesity (Silver Spring) 16: 2081-2087, 2008

18. Phan TT, Lim IJ, Chan SY, Tan EK, Lee ST and Longaker MT: Suppression of transforming growth factor beta/smad signaling in keloid-derived fibroblasts by quercetin: Implications for the treatment of excessive scars. J Trauma 57: 1032-1037, 2004.

19. Jung JC, Jang S, Lee Y, Min D, Lim E, Jung H, Oh M, Oh S and Jung M: Efficient synthesis and neuroprotective effect of substituted 1,3-diphenyl-2-propen-1-ones. J Med Chem 51: 4054-4058, 2008.

20. Heneka MT, O'Banion MK, Terwel D and Kummer MP: Neuroinflammatory processes in Alzheimer's disease. J Neural Transm (Vienna) 117: 919-947, 2010.

21. Kim MJ, Seung AR, Yoo JY, Jin CH,Lee YH, Kim YJ,Lee J, Jun WJ and Yoon HG: Gallic acid, a histone acetyltransferase inhibitor, suppresses $\beta$-amyloid neurotoxicity by inhibiting microglial-mediated neuroinflammation. Mol Nutr Food Res 55: 1798-1808, 2011.

22. Varadarajan S, Yatin S, Aksenova M and Butterfield DA: Review: Alzheimer's amyloid beta-peptide-associated free radical oxidative stress and neurotoxicity. J Struct Biol 130: 184-208, 2000.

23. Kadowaki H, Nishitoh H, Urano F, Sadamitsu C, Matsuzawa A, Takeda K, Masutani H, Yodoi J, Urano Y, Nagano T and Ichijo H: Amyloid beta induces neuronal cell death through ROS-mediated ASK1 activation. Cell Death Differ 12: 19-24, 2005.

24. Park SY, Kim HS, Cho EK, Kwon BY, Phark S, Hwang KW and Sul D: Curcumin protected PC12 cells against beta-amyloid-induced toxicity through the inhibition of oxidative damage and tau hyperphosphorylation. Food Chem Toxicol 46: 2881-2887, 2008.

25. Bonda DJ, Wang X, Perry G, Numonura A, Tabaton M, Zhu X and Smith MA: Oxidative stress in Alzheimer disease: A possibility for prevention. Neuropharmacololgy 59: 290-294, 2010. 